\title{
Review on Ethnomedical Uses, Pharmacological Activity and Phytochemical Constituents of Samanea saman(jacq.) Merr. Rain Tree
}

\author{
Shanmugam Vinodhini, Devi Rajeswari V*
}

\section{Shanmugam Vinodhini, Devi Rajeswari V*}

\section{Department of Biomedical Sciences,} School of Biosciences and Technology, VIT University, Vellore, Tamil Nadu, INDIA.

\section{Correspondence}

Dr Devi Rajeswari V

Department of Biomedical Sciences, School of Bio Sciences and Technology, VIT University, Vellore, Tamil Nadu, INDIA.

Phone no: 91-0416-2022326

E-mail: vdevirajeswari@vit.ac.in

History

- Submission Date: 17-10-2017;

- Review completed: 20-11-2017:

- Accepted Date: 19-12-2017

\section{DOI : 10.5530/pj.2018.2.35}

Article Available online

http://www.phcogj.com/v10/i2

\section{Copyright}

(C) 2018 Phcog.Net. This is an openaccess article distributed under the terms of the Creative Commons Attribution 4.0 International license.

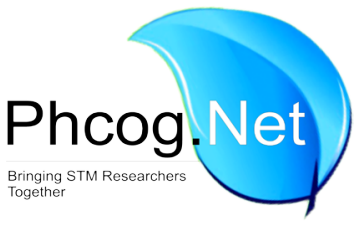

\begin{abstract}
Medicinal plants have been used as therapeutic drug throughout the world. But, a very few of them have been scientifically validated. Samanea Saman belongs to the Leguminosae family commonly known as rain tree and is native to tropical America. S. saman tree has different parts like a leaf, fruits, pods, seeds, and wood. S.saman is currently studied for the production of biogas which is easily obtained in the urban and rural areas. S. saman has been used in traditional medicine as a remedy for the treatment of different diseases. The phytochemical screening of the plant revealed the presence of alkaloids $-\mathrm{C}_{8} \mathrm{H}_{17} \mathrm{ON}$ and $\mathrm{C}_{17} \mathrm{H}_{36} \mathrm{ON}_{3}$ pithecolobine and saponin (samarin). Natural products are mainly derived from medicinal plants, which are tested in vitro and in vivo models and used to investigate the mechanism of action of drugs with potential biological properties. Additionally, S. saman were recommended as the suitable tree for planting in the urban environment as this species can reduce the outdoor temperature for all types of ground covers. This review is mainly focused on antioxidant, antibacterial, anti-diabetic potential, insecticidal, antifungal, analgesic, anti-ulcer and cytotoxic activities. However, this study helps to develop new strategies for the designing of novel drugs to treat various diseases related to human race.
\end{abstract}

Key words: Samanea saman, Pharmacological activities, Gas production, Nanoparticles, Chemical constituents.

\section{INTRODUCTION}

Medicinal plants have been used from ancient times to combat against different diseases from the daw, of human civilization. Medicinal plants are rich in secondary metabolites. In the middle of the 19th century different bioactive compounds were isolated and characterized from plants. ${ }^{1}$ According to the World Health Organization (WHO) in 2008, 80\% Population of the developing countries and facing difficulties to afford synthetic drugs ${ }^{2}$ and are relying on traditional medicines mainly of plant origin to maintain their health care needs. The World Health Organization (WHO 1985) ${ }^{3}$ supports the traditional medicine due to the inspiration of novel drug compounds from the natural source of plants. Such plants have derived medicines which made large contributions to human health and in both developing and developed countries have been great achievements in the field of herbal drugs because of their natural source and fewer side effects. ${ }^{4}$ The medicinal plant had shown an extensive interest in this field and it recognized that these natural products are true remedies for the human health benefits.

Various parts of the medicinal plant are used properly and scientifically it reaches worldwide. ${ }^{5}$ Plants have a potential source of natural antioxidants which includes secondary metabolites. ${ }^{6,7}$ Plants have been considered as the main source of antioxidant that inhibits the growth of free radicals. Ascorbic acid, flavonoids, tocopherols, folic acid, cinnamic acids, benzoic acids, tocotrienols, carotenoids etc., are some important antioxidants found in plants. ${ }^{8}$ Basically, ascorbic acid, alpha tocopherol, and Beta-carotene have generally used antioxidants because of its ability to scavenge the free radicals. ${ }^{9}$ The tribal areas of medicinal plants have valuable properties and most of the advantages are still restricted because of raw knowledge and absence of proper scientific validation. ${ }^{10}$ Natural bio-compounds of medicinal plants can be classified into Alkaloids, Cardiac glycosides, Steroids, Saponins, Tannins and Flavonoids. It is estimated that more than 250,000 to 500,000 species of higher plants on globe level were suggested as medicinal plants. ${ }^{11}$ Therefore, it is the need for the search of herbal materials that have potential activities against various diseases with less toxicity, free from side effects and would act as substitutes for synthetic drugs. Hence, it is assured that the S.saman presented in this review will be useful for researchers and practitioners to find potential natural agents.
Cite this article: Vinodhini S, Rajeswari DV. Review on Ethnomedical Uses, Pharmacological Activity and Phytochemical Constituents of Samanea saman(jacq.) Merr. Rain Tree. Pharmacog J. 2018;10(2):202-9. 
Samanea Saman (Jacq.) Merr, which is commonly known as "Rain tree" belongs to the Leguminosae family and also called as Albizia saman. ${ }^{12}$ Scientific classification of Taxonomy Kingdom: Plantae, Order: Fabales, Family: Fabaceae, Genus: Samanea Saman, Species: S.saman and exhibits the synonym names of S.saman such as Albizia saman, Enterolobium saman, Inga saman, Pithecellobium saman, and Mimosa saman. Rain tree is easily known for its characteristics like umbrella-shaped shelter. Rain tree is grown in the open and usually reaches $15-25 \mathrm{~m}$ (50-80ft) in height. ${ }^{13}$ S.saman is one of the most important plants in the Pacific as a shade tree on small farms and along road side areas in parks and pasture. The rain tree is grown in the tropical environment and its wood has limited use for carved bowls, craft wood, and fuel wood. The leaves and pods of rain tree are used as food due to the high nutritive content and nitrogen fixing capability. ${ }^{14} \mathrm{~A}$ huge number of uses are documented for S.saman, it naturalizes generously almost everywhere it has been introduced and is considered as an enveloping pest in Vanuatu and Fiji. The different therapeutic activities of S.saman have been reported..$^{15}$ S.saman shows several bioactive compounds which possess various medicinal properties such as antioxidants, antibacterial, anti-diabetic, analgesic, anti-ulcer, insecticidal, antifungal, and cytotoxic activities. ${ }^{16}$ Hence the present study on S.saman is focused on its phytochemicals and pharmacological activities.

\section{Origin and Distribution of Samanea Saman}

S.saman is widely distributed in the tropical and subtropical countries. Rain tree is extensively cultivated in throughout the worldwide S.saman is the native of Central America and in Northern South America. ${ }^{17,18}$ It is widespread in Thailand, ${ }^{19}$ Peru, Brazil, Bolivia and Mexico. ${ }^{20,21}$ In these above-stated areas, it occurs in low-elevation dry forests and grassland habitats.

\section{MORPHOLOGY AND DESCRIPTION OF PLANT}

Figure1 shows different parts of the S.saman (a) leaves, (b) flowers, (c) barks and (d) pods.

\section{Leaves}

Leaves are alternately arranged along with twigs and have a prominent swelling at the petiole base. The size of the leaf is $2-4 \mathrm{~cm}$ elongated and $1-2 \mathrm{~cm}$ broad. The largest apical fliers and foliage are arranged in 2-6 pairs of pinnae and each pinna bearing 6-16 diamond shaped leaflets and has a yarn like stipules present in the leaves. The shape of the leaf looks like blades and is twice even pinnately complex. The leaf contains silkysmooth condition with a circular gland. Glossy green on the top of the leaf, thinly hairy beneath in bottom and it looks dry and dull for a short era. The S.saman trees are semi-deciduous and lose their leaves, during the period of summer. It is the reason for which it remains leafless for a period, but quickly defoliate if there is sufficient moisture. This gives the appearance that $S . s a m a n$ (rain tree)is "evergreen" in moisture climates. ${ }^{22}$

\section{Flowers}

The flowers of S.saman are tiny. 12-25 flowers Per-head are massed, and it looks pinkish-red in colour; head of the flower is $5-6 \mathrm{~cm}$ crosswise and $4 \mathrm{~cm}$ in height. Flowers are pinkish-red in above and white in interior and it gives the fluorescence hairy. Flowers have a feather duster or powder puff appears held slightly above the foliage. Thousands of heads are born eat the same time and covering the tree in pinkish blossom..$^{22,23}$

\section{Fruit}

Mature pods (monkey pods) are blackish- brown in colour quadrilateraland its shape is straight or slightly bowed. The size of the pods is $10-20 \mathrm{~cm}$ long and wide $15-19 \mathrm{~cm}$ and it filled with brownish pulp. ${ }^{22}$

\section{Bark}

The bark of the mature tree is grey, rough fissured in long plates. The inner bark is a light colour and bitter. On younger trees, the bark is smoother and pale gray to brownish in colour ${ }^{22}$

\section{CHEMICAL CONSTITUENTS}

A Literature search on the chemical constituents of S.saman bark revealed the presence of two different compounds of alkaloids $-\mathrm{C}_{8} \mathrm{H}_{17} \mathrm{ON}$ and $\mathrm{C}_{17} \mathrm{H}_{36} \mathrm{ON}_{3}$ (pith colobine, and a saponin samarin). Some other constituents are identified in the bark are sucrose, glucose, gallic acid, fatty acids, phytosterol, octacosanoic acid, lupeol, $\alpha$-. spinasterol, $\alpha$-spinasterone and lupenon. Figure 2 and 3 shows the chemical composition of S.saman ${ }^{24,25,26}$

\section{MEDICINAL USES OF SAMANEA SAMAN}

The different folk remedies prepared from various parts of S.saman. It is a folk medicine used as the remedy for a headache, cold, diarrhoea, stomach-ache intestinal ailments, sore throat, and stomach cancer. The boiled bark is used as a bandage to cure constipation. The decoction of bark (inner) and leaves is used for diarrhoea. In Venezuela, the roots are made into a hot bath for stomach cancer and in the West Indies; the seeds are chewed for a sore throat. The antimicrobial activity of this plant has been reported against some pathogens that affect human and few plant pathogenic fungi and bacteria. S.saman is also known to have antioxidant, anti-plasmodial, and cytotoxic properties. ${ }^{27,28,29}$

Leaves: Solvents extract of S.saman leaves inhibits Mycobacterium tuberculosis and alkaloid fraction of the leaf is effective on the (CNS) central nervous system and peripheral nervous system (PNS). A leaf infusion is used as a laxative and for diarrhoea. Fruits: Fruit decoction is used as a (CNS) central nervous system -sedative; S.saman plant is also used for diarrhoea, colds, headache, intestinal ailments, and stomach-ache, and pain, intestinal ailments treating the ulcer and bleeding disorders. ${ }^{30,31,32}$ Bark: It used for diarrhoea and root is used for stomach cancer. At present, research is focussed on using leaves and bark of the plant and its organ protection properties. ${ }^{22,23,24,25}$

\section{ISOLATION OF COMPOUNDS FROM VARIOUS PARTS OF SAMANEA SAMAN}

In view of increasing interest for these herbal drugs ${ }^{29}$ two compounds were isolated from the crude methanol extract of S.saman, namely Lupeol and epi-lupeol. Compounds were analysed by TLC and high-resolution NMR spectral data with authentic samples. The preliminary screening on, carbon tetrachloride, $\mathrm{n}$-hexane and a dichloromethane soluble fraction of methanolic extract was analysed for antimicrobial activity and brine shrimp lethality bioassay. While the carbon tetrachloride extract showed a moderate result in antimicrobial activity and strong cytotoxicity with $\mathrm{LC}_{50}$ of $0.831 \mu \mathrm{g} / \mathrm{ml} .{ }^{33}$ Various other compounds were isolated from different parts of S.saman extract of dichloromethane. The structures were identified by NMR spectral data, $1 \mathrm{H}$ (or) 13C NMR. Compounds identified in leaves are Lupenone, chlorophyll, and Lupe none, and from twigs unsaturated triglycerides, peduncle; $\alpha$-spinasterone and $\alpha$-spina sterol.

\section{NANOPARTICLES AND ITS BIOSYNTHETIC IMPORTANCE}

Nanotechnology is the most important area of advance research dealing with synthesis, design, and range of the particle structure is approximately $1-100 \mathrm{~nm} .{ }^{34}$ The investigation revealed that nanoparticles have gained much attention because of its significant properties such as electronic, magnetic, photocatalytic, and semiconducting etc Nanoparticles have a 
huge applications such as health care, environmental health, cosmetics, food and feed, biomedical sciences, drug-gene delivery, chemical industries, optoelectronics, photoelectrochemical applications and etc. ${ }^{35}$ These methods are still in the initial stage and some experienced problems are stability and aggregation of the nanoparticles, size distribution, morphology and growth of the crystal. ${ }^{36}$

Furthermore, the extraction and purification of synthesized nanoparticles are used for the various applications, but still an important issue. Nanotechnology is a major research area and which have combined with the plant source of green synthesis. This eco- friendly and green synthesis method does not cause lethal effects to the environment. Now a day, there is a need to grow in the development of eco-friendly processes. ${ }^{37,38}$ Green synthesis methods have advantages such as mixed valence of polysaccharide, polyoxometalates and conventional methods are involving in chemical agents related to environmental toxicity. The most important issues are considered in green synthesis of nanoparticles, based on the selection of solvent medium and selection of eco-friendly nontoxic reducing and stabilizing agents. ${ }^{39}$ This eco-friendly method can be potentially used in the different fields. In this study, S.saman mediated synthesis of TiO2 nanoparticles. ${ }^{40}$ have utilized leaf extract for the preparation of $\mathrm{TiO} 2$ nanoparticles. The authors stated that secondary metabolites were responsible for the reduction of bulk $\mathrm{TiO} 2$ to $\mathrm{TiO} 2$ nanoparticles. Further, they were subjected to dye degradation and in water treatment.

\section{PHYTOCHEMISTRY}

This study was conducted to determine the antioxidant properties and preliminary phytochemical analysis of two different extracts of Albizia saman leaves. Shade dried leaves were powdered for extraction and defeated with methanol and petroleum ether extract. The results showed that methanolic extract contains bio-constituents such as alkaloids, carbohydrates, and glycosides, reducing sugar, saponins, steroids, tannins, and flavonoids. ${ }^{41}$ Phytochemical screening analysis of S.saman aqueous extract has shown the presence of saponins, cardiac glycosides, tannins; flavonoids, steroids, and terpenoids. ${ }^{31}$ Various Crude dry powder samples were analysed such as ash value, solubility, extracting value, fluorescence analysis, qualitative and quantitative phytochemical analysis. The mineral contents of the plant have been studied using three different solvents and among them, the ethanolic extract showed good results in the qualitative analysis. ${ }^{42,43}$ The author has been demonstrated phytochemical screening analyses of pods extract of $n$-hexane and it was extracted with $70 \%$ of aqueous and acetone yielded for characteristics. It shows solid tannins of reddish brown colour. In qualitative and quantitative screening analysis results showed that tannins were condensed, and the sample was performed paper chromatography using three different combinations of mobile phase such as glacial acetic acid, $n$-butanol and distilled water (1:4:5) and the result showed that the identified to be tannins, catechin, epicachin, cyaniding, anthocyanin, monoglycones, malidin and delphinidin. ${ }^{44}$

\section{PHARMACOLOGICAL ACTIVITIES}

\section{Antioxidant Activity}

Free radical causes oxidative damage to the human body and finally leads to chronic diseases. ${ }^{45}$ Moreover, free radicals such as reactive oxygen species (ROS) and reactive nitrogen species (RNS) are produced by heat and endogenous processes such as metabolism, respiration and phagocytosis and they are also generated with exogenous methods such as during radiation, organic solvents, pesticides and some pollutants. Antioxidant associated with lower risks of degenerative disease, mainly in cardiovascular disease and cancer etc. ${ }^{46}$ A Natural antioxidant is a group of the compound that inhibits the oxidation of lipids and other bio molecules and therefore prevents the oxidation damage to body cells. ${ }^{47}$ Antioxidants are considered as important to the human health. In recent years, many medicinal plants have been widely studied for their antioxidant activity. There are several benefits of antioxidant which have clearly shown in the Figure 4 (a), (b). Different studies were focused on the medicinal plants and their applications in the food system to prevent the oxidation.

Methanolic extract of Albizia saman has shown the protective role of on antioxidant activity was measured in (DPPH) 2,2-diphenyl-1-picrylhydrazyl (DPPH) radical scavenging capacity, reducing power and total antioxidant capacity of Albizia saman were determined by phosphor molybdenum method and the result shows good antioxidant properties and it also supports the use of Albizia saman in herbal medicine. ${ }^{41}$ In another study, the alcoholic extract of S.saman was assayed for their antioxidant activities, 70 percent of alcoholic extracts have been investigated in various assays of reducing power and Nitric oxide radical scavenging activity. These results indicate that S.saman can be used in this application. It showed scavenging activity against the standard of ascorbic acid.

In literature, ${ }^{28}$ survey the role of antioxidant activity was performed in different solvent extracts. In this investigation showed that presence of phytochemicals elements and antioxidant activity of reducing power assay and (1,1 diphenyl-2-picrylhydrazyl) DPPH radical scavenging assay, the following orders of the different solvent extract are petroleum ether, ethyl acetate, chloroform, aqueous and hydrochloric acid extracts it exposed in increasing concentration. DPPH scavenging activity present in the extract it shows $68 \%$ in $10-15 \mathrm{mg}$

Afia Ferdous et al. Report stated that S.saman methanolic bark extract was subjected to the fractions of chloroform, n-hexane, and carbon tetra chloride. Methanolic extract was tested for antioxidant assays of total antioxidant activity, free radical scavenging and DPPH assay and standard is used as the Ascorbic acid. The results show that high antioxidant activity in hexane soluble fraction IC $50=14 \mu \mathrm{g} / \mathrm{ml}$ and IC $50=65 \mu \mathrm{g} / \mathrm{ml}$ moderate antioxidant activity in the fraction of carbon tetra chloride followed by the fraction of hexane and chloroform..$^{48}$

\section{Antimicrobial Activity}

S.saman is a tropically distributed medicinal plant. ${ }^{31}$

Crude aqueous extract of S.saman showed antimicrobial activity when tested against three different organisms such as Escherichia coli, Staphylococcus aureus, and Candida albicans. Different solvent extracts of S.saman like dichloromethane, ethyl acetate, and ethanol extracts were investigated against various pathogenic microorganisms S.aureus, E.coli and C.albicans using different methods like disc diffusion, Well diffusion, streak plate, and dilution methodology. The various solvents were removed to yield a paste form that was assessed for activities. The extracts were made up to the concentration of $0.035 \mathrm{~g}$ in $(10 \mathrm{~mL})$ of the various solvents. These tested in different volumes of $0.2-0.6 \mathrm{ml} /$ plate, while the concentrations of $0.03-0.18 \mathrm{mg} / \mathrm{ml}$. Penicillin and fungicide used as a control reference for a microorganism. S.saman showed selective antimicrobial activity, in most outstanding results for the ethanol and dichloromethane extract and insignificant with the dissolving agent. In this study, dichloromethane extract was found to show stronger antimicrobial activity than the ethyl acetate extract. This study suggests that the ethanol and dichloromethane extracts of rain tree can be used as medicine for the control of organisms such as E. coli and S. aureus and C. albicans induced diseases, following clinical trials. ${ }^{49}$

In 2011, the author tested the antimicrobial activity of six different solvent extracts of S.saman. The result exposed that the highest antibacterial activity in the methanolic extract and its range of zone of inhibition is $11.0 \mathrm{~mm}$ to $30.5 \mathrm{~mm}$ at $1 \mathrm{mg} / \mathrm{ml}$ concentration. The MIC value of methanol extract was tested with bacteria, in the concentration range between $156 \mathrm{~g} / \mathrm{ml}$ to $5006 \mathrm{~g} / \mathrm{ml}$. The most susceptible microbes are Streptococcus 
faecalis (MIC 156g/ml) followed by Staphylococcus aureus (MIC $626 \mathrm{~g} / \mathrm{ml}$ ), while the most resistant was Proteus vulgaris (MIC 5006g/ml). The extremely vital antifungal activity was also observed in the $1 \mathrm{mg} / \mathrm{ml}$ concentration of methanolic extract. The percentage (\%) inhibition ranges $20.4 \%$ to $81.6 \%$. Methanol extracts ranges from $0.3 \mathrm{mg} / \mathrm{ml}$ to $5 \mathrm{mg} / \mathrm{ml}$. In the test for fungal species, it showed Fusarium moniliform was highly sensitive $\left(\mathrm{IC}_{50} 0.3 \mathrm{mg} / \mathrm{ml}\right)$ and Aspergillus tamari was least sensitive. ${ }^{50}$

Three different solvents were used by based on the increasing polarity of benzene, ethyl acetate, and methanol in different ratios. TLC analysis has been used to monitor the fractions, that similar fractions were subjected to antimycobacterial activity. The result was observed at the concentration of $20 \mu \mathrm{g} / \mathrm{ml}$ and the ratio of 80:20 ethyl acetate: methanol reveals the antimycobacterial activity. This fraction was reported to be completely resistant against Aspergillus Niger and Pseudomonas aeruginosa. Samples have been subject to UV and IR analysis to identify the absorbance and functional group correspondingly. ${ }^{51}$ In literature, ${ }^{52}$ author isolated the compounds and performed an antimicrobial activity against different strains, using 80 percent (\%) of methanol extract of S.saman leaves. The isolated compounds are known as macrocyclic pith colobines (1) and (2), and macro cyclic spermine alkaloids. Compounds structure was analysed by spectrum and it was compared with literature survey. The test was performed using disk diffusion method. As a result, it was observed that 80 percent (\%) of methanolic leaves extract has shown the inhibitory activity. It against most common microorganisms such as g-positive bacterium Bacillus subtilis and four different fungi Aspergillus flavus, Aspergillu Niger, Penicillium oxalicum and Cladosporium oxysporum isolated from sick buildings. MIC test shows that isolated two compounds act against the microbes, alkaloid (2) range is $0.019-0.625 \mu \mathrm{g} / \mathrm{ml}$ and alkaloid (1) $0.312 \mathrm{mg} / \mathrm{ml}$ inhibited the Bacillus subtilis. Microbial activity has been traced to the isolated compounds such as an alkaloid pith colobine (1) and (2) is using orderly the fractionation directed by antimicrobial assay Figure 5.

\section{Anti-diabetic Activity}

Diabetes mellitus is a non-communicable disease with multiple disorders characterized by a loss of glucose homeostasis with disturbances of carbohydrates, protein and fat metabolism ensuing from defects in insulin action, insulin secretion, or both..$^{53}$ In worldwide, more than 100 million people are affected by diabetes and are considered as the leading causes of death in the world. ${ }^{54} \mathrm{~A}$ lot of researchers and investigation are focused on the anti-hyperglycaemic activity of plant origin reported in the traditional medicine. ${ }^{55}$ In previous studies, many of them have been found to possess the positive results. Various standard drugs that are available in the market to reduce the glucose level may cause side effects. Therefore searching for a new medicinal plant with bio-constituents is necessary ${ }^{56,57}$ reported that selected medicinal plant S.saman methanol leaves extract showed anti-diabetic activity in both in vitro and in vivo studies. In this $\alpha$-amylase inhibition it shows various increasing concentrations are $50 \mu \mathrm{g} / \mathrm{ml}, 100 \mu \mathrm{g} / \mathrm{ml}, 150 \mu \mathrm{g} / \mathrm{ml}, 200 \mu \mathrm{g} / \mathrm{ml}$, and $250 \mu \mathrm{g} / \mathrm{ml}$. Two different concentrations of methanol extract, 250 and $500 \mathrm{mg} / \mathrm{kg}$ body weight of doses were administrated to diabetic induced rats. Significantly it could reduce the blood glucose level $(p<0.001)$ at 1 and $2 \mathrm{hrs},(p<0.05) 30 \mathrm{mints}$ respectively and it was compared to the control group of diabetic induced rats. Thus, this new class of bio- constituents may be suitable for the treatment of diabetes mellitus.

\section{Anti-Inflammatory Activity}

Inflammation is a natural response to tissue injury which is caused by physical trauma, toxic chemicals, and pathogenic microorganism. It can be characterized by redness, swelling, and pain. Cyclooxygenase (COX) is an enzyme, which is involved in the synthesis of prostaglandins,
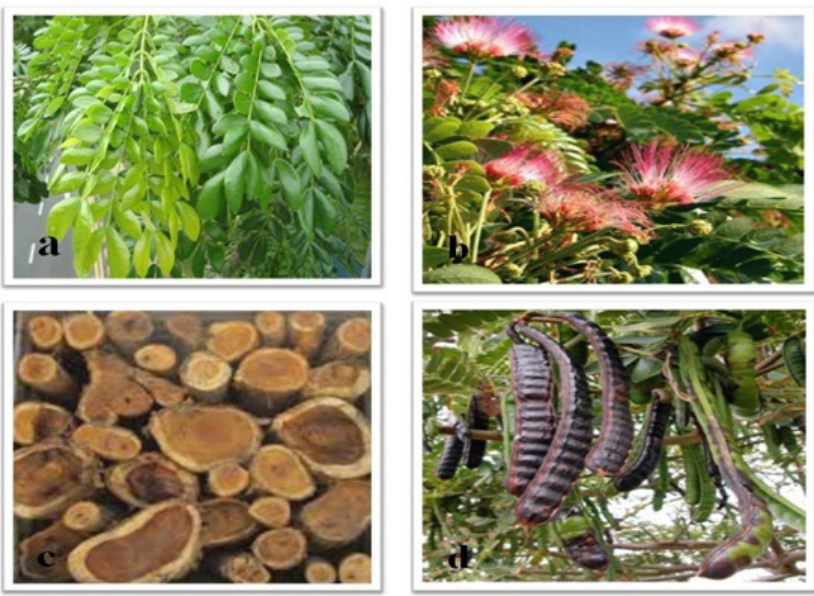

Figure 1: Different parts of the Samanea Saman (a) leaves, (b) flower, (c) bark and (d) pod.

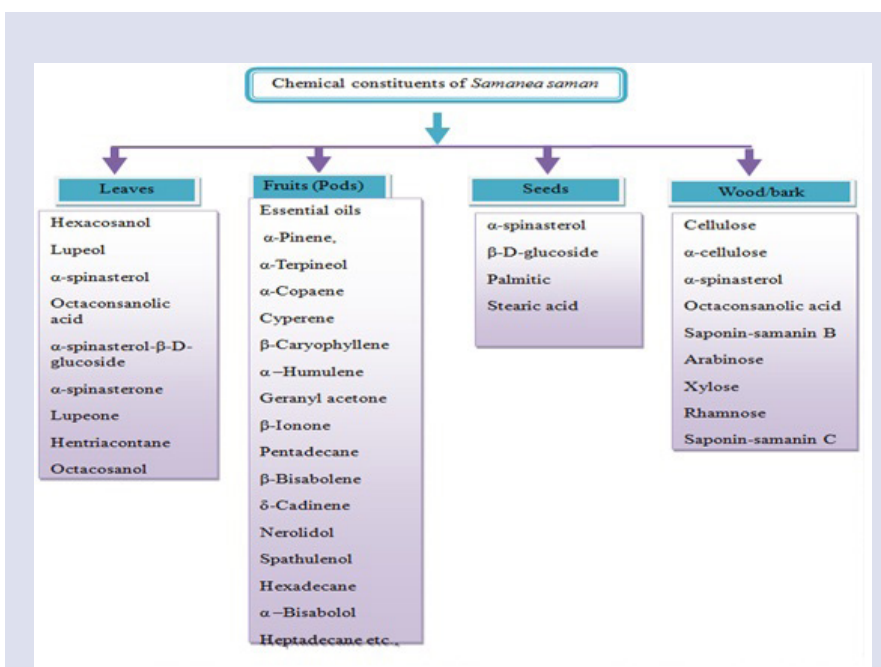

Figure 2: Chemical constituents of Samanea Saman.
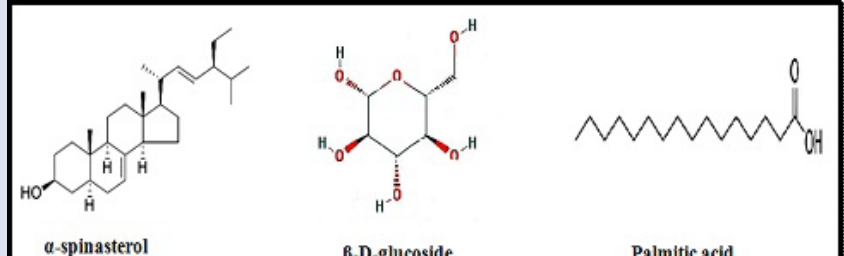

a-spinasterol

B-D-glucoside

Palmitic acid

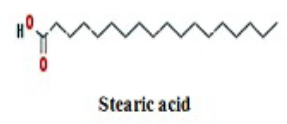

(b). Samanea saman Seeds compound structure

Figure 3: Chemical structures of the bioactive compounds from Samanea Saman various parts (a) leaves 


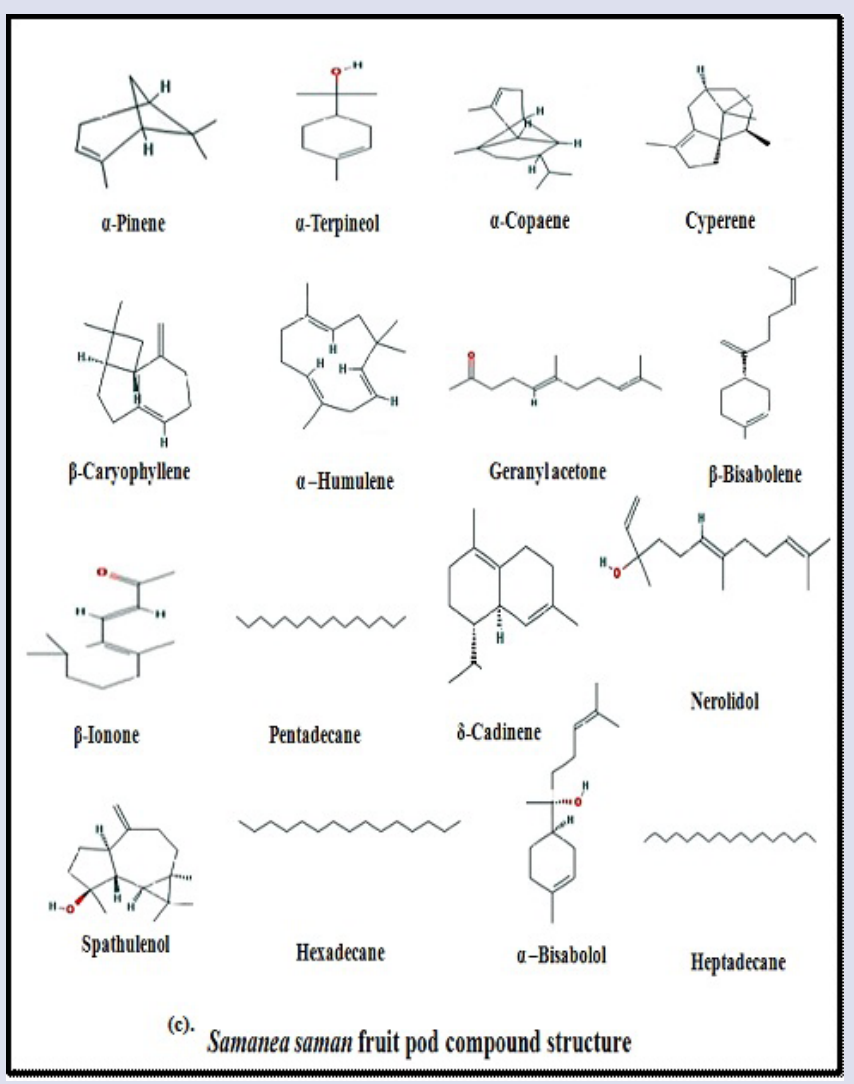

Figure-3 (c): Chemical structures of the bioactive compounds from Samanea Saman various part (c) (fruit pod)

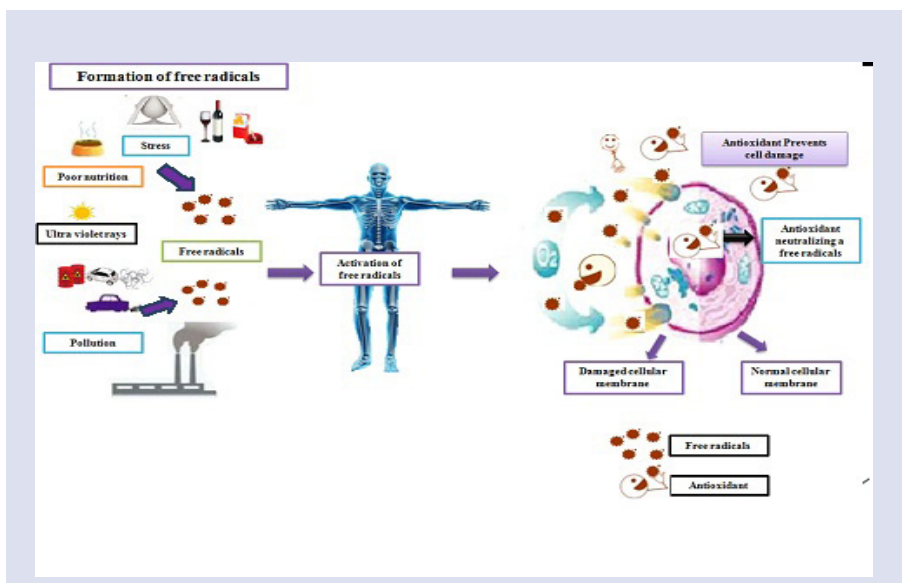

Figure 4(a): Formation of free radicals and antioxidant role

prostacyclin's, and thromboxane's for the inflammation. Currently, NSAIDs drug is used for the reduction of inflammation by blocking COX1 and COX2 enzyme activity. Since NSAIDs is a steroidal antiinflammatory drug that cause adverse side effects and damage the human biological system. So, there is a need of potent and nontoxic anti-inflammatory drug. WHO has reported that about $80 \%$ of the world population depends on plant based drugs. ${ }^{58}$ has reported the anti-inflammatory activity of methanolic extract S.saman bark. The results showed that five

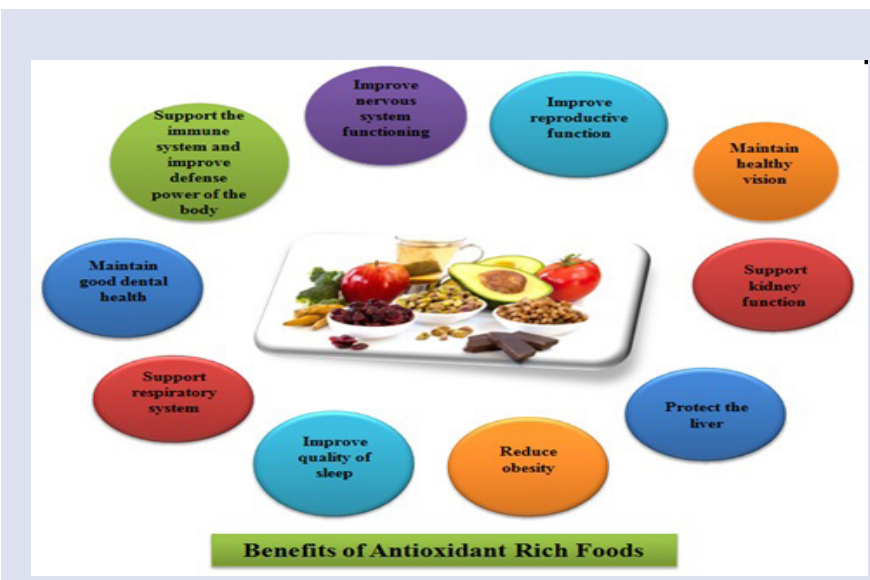

Figure 4(b): Benefits of antioxidants

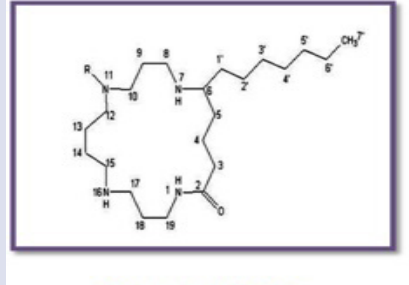

Pithecolobine 1: $\mathrm{R}=\mathrm{H}$

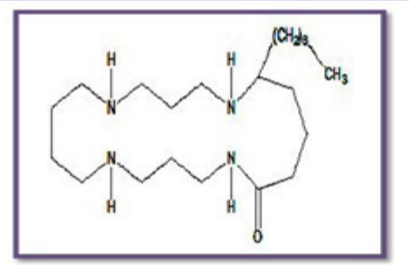

Pithecolobine $2: \mathrm{R}=\mathrm{OH}$
Figure 5: Chemical structures of the bioactive compound Pithecolobine

different concentrations $(0.25,0.5,1,2,4 \mathrm{mg} / \mathrm{ml})$ have the inhibition of $51 \%$ haemolysis at the highest concentration, and it has been compared to the standard drug of diclofenac sodium which has $29 \%$ inhibition of haemolysis. Therefore, the presence of phytoconstituents such as flavonoids, tannins and phenolic compounds and glycosides in this S.saman extract may be responsible for anti-inflammatory activity and be used in this file, followed by a clear scientific investigation.

\section{Anti-Ulcer Activity}

Ulcer disease is considered as one of the most common diseases in the world. It is a gastro intestinal disorder due to an imbalance between the aggressive factors like acid, pepsin, Helicobacter pylori and defensive factors like bicarbonate secretion, prostaglandins, gastric mucus, and innate resistance to the mucosal cell factors. Generally, ulcer develops when aggressive factors overcome the defensive factors. The major factors that disrupt the equilibrium between aggressive factors and defensive factors are Helicobacter pylori, acid-pepsin hyper secretion, non-steroidal anti-inflammatory drugs, sometimes idiopathic due to usage of tobacco, psychological stress, rapid gastric emptying, and Zollinger - Ellison syndrome where there is a high and uncontrollable production of acid might lead to ulcer formation, ${ }^{59}$ has investigated the methanol extract of S.saman bark and evaluated its anti-ulcer activity. Stress induced by Gastric lesions was induced in albino rats by oral administration of absolute ethanol $(5 \mathrm{~mL} / \mathrm{kg})$ and stress by water immersion. Various concentrations of methanolic extracts are $100 \mathrm{mg} / \mathrm{kg}, 200 \mathrm{mg} / \mathrm{kg}$ and $400 \mathrm{mg} / \mathrm{kg}$ and it was compared to standard drug of sucralfate $(100 \mathrm{mg} / \mathrm{kg})$. The result shows \% inhibition at $65.67,72.43$ and 86.49 and $(100 \mathrm{mg} / \mathrm{kg})$ standard 
drug sucralfate shows the inhibition of 92.16 . Methanolic extract $200 \mathrm{mg} / \mathrm{kg}$ and $400 \mathrm{mg} / \mathrm{kg}$ body weight exhibited the significant values $(\mathrm{P}<0.001)$ showed on acid parameters and it was compared to the ulcer control group and in water immersion it showed the significant value $(\mathrm{P}<0.001)$, $\%$ inhibition of $53.30,71.11$ and 87.69 to $100 \mathrm{mg} / \mathrm{kg}, 200 \mathrm{mg} / \mathrm{kg}$ and $400 \mathrm{mg} / \mathrm{kg}$ and standard exhibited 92.68 . Hence the methanol extracts of S.saman exhibits anti-ulcer activity.

\section{Anti-Anxiety Activity}

Shilpa et al. conducted the experiments to assess the anti-anxiety effects of various extracts of S.saman to be used for central nervous system (CNS) disorders. The extraction process was done with three different solvents such as chloroform, methanol and aqueous. Antianxiety activity was carried out in mice using elevated plus maze and (Rotarod apparatus). In mice, $200 \mathrm{mg} / \mathrm{kg}$ body weight of methanol extract and diazepam as a (standard drug) $2 \mathrm{mg} / \mathrm{kg}$ body weight were administered. Amid all three extracts tested, methanol extract shows significant anti-anxiety activity. ${ }^{43}$

\section{Insecticidal Activity}

Insecticidal activity of the leaf extract of S.saman has been carried out by the four different insects like Callosobruchus analis, Rhyzopertha dominica, Tribolium castaneum and Tribolium granarium. Extraction was done with different solvents like methanol and hexane. The result suggested that insecticidal activity of methanol extract shows inactive against all the tested insects and hexane extract showed 50\% mortality against and Tribolium granarium and Rhyzopertha dominica. ${ }^{60}$

\section{Cytotoxic Activity}

The author has isolated the compounds from $80 \%$ methanolic extract of S.saman leaves. Leaves are acquiesced two macrocyclic spermine alkaloids-Pitheceolobine -1-2 compounds and these two structures are clarified by spectral analysis. ${ }^{51}$ The two compounds were reported to exhibit good cytotoxic activity, and the range of concentration is 0.019 $0.625 \mathrm{mg} / \mathrm{mL}$. In literature clearly indicated the cytotoxicity $757.3672 \mu \mathrm{g} / \mathrm{ml}$ of methanol extract in brine shrimp bioassay, with the $\mathrm{LD}_{50}$ value of $757.3672 \mu \mathrm{g} / \mathrm{ml} .^{60}$

\section{Allelopathic Activity}

Allelopathy is a biological phenomenon and refers to some process involved to produce the (allelochemicals) secondary metabolites from plants, microorganisms, fungi and viruses that influence the growth of agriculture and biological methods including the positive and negative effects. ${ }^{61,62}$ Allelochemicals that released into the environment by exudation as of roots, leaching from stem and leave. Allelopathy, a new strategy for plants has some important mechanism of plant meddling mediate by the addition of plant produced (phytotoxins) to the plant environment ${ }^{63,20}$ have tested the allelopathic effect of S. saman and three different medicinal plants namely Amaranthus viridis, Brassica campestris, Oryza sativa. Various concentrations of samples were taken as a 0,1,2 and 4 percentage. The leaf leachate effect on germination seeds was studied. Results exposed that the plant S.saman has the inhibitory effect on Brassica campestris, and Amaranthus viridis, while rice plant of Oryza sativa is opposed to the effect of leaf leach ate.

\section{Hepatoprotective Activity}

The largest organ in the human body is liver and it is the site of metabolism and excretion. The surprising role of the liver is performance, maintenance, regulating homeostasis of the body and involving in almost all the biochemical pathways. ${ }^{64}$ The liver is the major function junction of carbohydrates, proteins, and fat metabolism, bile secretion, storage of vitamins and detoxification. Liver diseases have become a global health problem and it causes a significant amount of morbidity and mortality. ${ }^{65,66}$ Liver disease is classified as the acute or chronic disease like cirrhosis of degenerative disorder resulting in liver fibrosis, hepatitis of inflammatory liver diseases and hepatosis of non-inflammatory diseases. ${ }^{67}$ Synthetic drugs for the treatment of liver disease sometimes may cause serious side effects. As in earlier days, mankind has complete use of the medicinal plant to treat the various ailments as their toxicity must lower side effects. In literature ${ }^{68}$ focused their research on the hepatoprotective activity of methanol extract of S.saman against albino rats with liver damage induced by carbon tetrachloride. $400 \mathrm{mg} / \mathrm{kg}$ body weight of methanol extract was administrated into rats and it reduces the serum level of ALT, AST, and cholesterol. While in the serum, enzyme activity shows the significant increase in the levels. Blood samples were estimated on liver injury caused by carbon tetrachloride and it shows the resulting decrease in the serum levels, representing the production of hepatic cells.

\section{PHARMACEUTICAL AND NUTRACEUTICAL VALUES OF FRUIT PODS}

In this study, the fruit pods of S.saman contain various kinds of beneficial polyphenols such as Cyandin, catechin, epicachin, anthocyanin, monoglycones, delphinidin and malidin. Usually, pods are discarded, after consuming edible parts. Fruit pod contains polyphenolic compounds that endorse the antioxidants. Moreover, some other biological activities include antibacterial, antifungal, anti-inflammatory and chemo preventive properties which connected to the fruit pods. Some potential sources of pharmaceutical compounds are carotenoids, saponins, and xanthomas. This study will be very helpful to identify the useful sources of nutraceutical and other pharmaceutical components. ${ }^{69}$

\section{RAIN TREE PODS FOR A GAS PRODUCTION}

The author investigated the effect of S.saman fruit pods on the meal concentration by the production of gas in (in vitro) fermentation method. S.saman Pods have been taken at various levels of concentrations 20,40,60,80 and 100 percent. Gas production was monitored for every h up to $72 \mathrm{hr}$ of incubation. The study evaluates the production of ammonia nitrogen (NH3-N), butyrate (C4), propionate (C3), acetate (C2), total volatile fatty acids (TVFAs). In vitro true digestibility (IVTD) and showed a significant value $(\mathrm{p}<0.05)$. Results of the in vitro study of S.saman exposed that it might be an alternative feedstuff for ruminants and perhaps a replacement meal, when the concentration is below $60 \%$, without any negative consequence based on pods. ${ }^{19}$

Recently, the requirement of bio ethanol is increased, therefore the production of bio ethanol must be increased by using raw materials because it is eco-friendly and economically affordable. It is known that fruits and vegetable wastes are cheaper and eco-friendly. A previous study selected some fruits and vegetable wastes and also S.saman pod waste to produce the bio ethanol by using (yeast) Saccharomyces cerevisiae and the results obtained a showed higher rate of ethanol production through fermentation. S.saman pod waste provides a good percentage of ethanol production as compared to other wastes. Results suggested that S.saman wastes contain rich fermentable sugar which can be converted into bio ethanol and can also serve as an energy source. Pod waste was also used in the production of bio ethanol and emission of ethanol combined diesel fuel. The fuel had been conducted on single cylinder four stroke CI engines, which was operated at pressure 210 bar with the speed $1500 \mathrm{rpm}$. It provides evidence that pods of S.saman have the ability of gas production. ${ }^{70}$ 


\section{USES OF SAMANEA SAMAN}

- Leaf contains $22-27 \%$ of crude protein. In Asian countries are used as a livestock forage supplement for cattle etc.

- Nutritional values of the pod that contains $12-18 \%$ protein, the pod are ground into a nutritious animal feed in South American.

- The fruit pulp is used to make a beverage in Latin America and it is a minor food item for human, while the pods have a nice flavour. ${ }^{22}$

\section{CONCLUSION}

Plants have a natural source of medicines to treat various types of diseases, but still many plants have not been well characterized. S.saman is a multipurpose tree, adaptable to tropical conditions and with great potentiality act as alternative feed for ruminants and monogastric. In this review, hereby conclude that S.saman also showed a broad range of pharmacological activities such as antioxidant, antibacterial, anti-diabetic potential, insecticidal, antifungal, and analgesic, anti-ulcer and cytotoxic activity and effects due to the presence of phytoconstituents. Further study must be carried out to assess the exact mechanisms involved in S.saman and it also contains natural compounds. Isolation and characterization of such specific may be used to treat the targeted gene or enzyme. This further leads to the development and discovery of novel traditional medicine against various diseases without any adverse effect.

\section{ACKNOWLEDGMENT}

The author thanks the VIT University for providing all the research facilities and support to carry out research process.

\section{CONFLICT OF INTEREST}

The authors declare that they have no competing interests.

\section{ABBREVIATION USED}

WHO: World Health Organization; CNS: Central Nervous System; PNS: Peripheral Nervous System; NMR: Nuclear Magnetic resonance; TLC: Thin layer chromatography; DPPH: 2,2-diphenyl-1-picrylhydrazyl; Tio2: Titanium dioxide; ROS: Reactive Oxygen Species; RNS: Reactive Nitrogen Species; MIC: Minimum inhibitory concentration; COX: Cycoloxygenase; ALT: Alanine transaminase; AST: Aspartate transaminase; TVFAS: Total Volatile fatty acid; IVTD: In vitro True Digestibility.

\section{REFERENCES}

1. Phillipson JD. Phytochemistry and medicinal plants. Phytochemistry. 2001;56(3):237-43

2. Vickers A, Zollman C. ABC of Contemporary Medicine. Herbal Medicine. B Med J. 1999;319(7216):1050-3.

3. Grieve MA, Modern herbal. Hafner press, New York, 915 pp. Dover reprint; 2vols. First reprinted 1971.Dover; 1931; New York, 902 pp.

4. Pandavadra M, Chanda S. Development of quality control parameters for the standardization of Limonia acidissima L. leaf and stem. Asian Pac J Trop Med. $2014 ; 7(1):$ S244-8

5. Pisoschi AM, Pop A. The role of antioxidants in the chemistry of oxidative stress. A review European Journal of Medicinal. 2015;97:55-74.

6. Niki E. Assessment of Antioxidant Capacity in vitro and in vivo. Free Radical Biology and Medicine. 2010;49(4):503-15

7. Alam MN, Bristi NJ, Rafiquzzaman M. Review on in vivo and in vitro methods evaluation of antioxidant activity Md. Saudi Pharmaceutical Journal. 2013 21(2):143-52.

8. Walton NJ, Brown DE. Chemicals from plants: Perspectives on plant secondary products, London: Imperial College press. 1993

9. McCall MR, Frei B. Can antioxidant vitamins maternally reduce oxidative damage in humans Free Radical. Biology Med. 1999;26(7):1034-53.

10. Acalypha-Racemosa et al. Comparison of in vitro antioxidant properties of extracts from three plants used for medical purpose in Cameroon. Asian Pac. J Trop Biomed. 2014;4(2):S625-32.
11. Taylor L. Plant Based Drugs and Medicines. Raintree Nutrition Inc. Carson City, NV. 2000.

12. Durr PA. The biology, ecology and agroforestry potential of the rain tree Samanea Saman (Jacq) Merr. Agroforest. Syst.2001;51(3):223-37.

13. Kabir M, lqbal ZM, Shafiq M. Traffic Density, Climatic Conditions and Seasonal Growth of Samanea Saman (Jacq.) Merr. On Different Polluted Roads of Karachi City, Pak J Bot. 2012;44(6):1881-90.

14. Muthuchelian K, Meenakshi V, Nedunchezhian N. Protective effect of triacontanol against acidic mists in Samanea Saman (Jacq.) Merrill seedlings: Differential responses in growth, 14CO2 fixation, ribulose-1,5-bisphosphate carboxylase, and electron transport activities. Photosynthetic. 2003;41(3):335-41.

15. Clarke WC, Thaman RR. Agroforestry in the pacific islands: systems for medicinal sustainability. United Nations. University Tokyo. 1993;53-70.

16. Anonymous. International: Medicinal compendium.CAB International Wallingford. UK. 2003

17. Allen ON, Allen EK. The Leguminosae, University of Wisconsin Press. 1981; P.812

18. Woodson RE. Schery RW. collaborators. Flora of Panama. Pt 5, fasc 2. Ann. Missouri Bot. Garden. 1950;37:121-314

19. Semae S, Kongmun $P$, Vajrabukka $C$, Chanpongsang S, Prasanphanich S. Effects of Different Levels of Rain Tree (Samanea Saman) Pods in Meal Concentrate on In vitro Fermentation by a Gas Production Technique, Kasetsart. J Nat Sci. 2013:47:704-11.

20. Ghosh S, Molla KA, Ghosh K. Allelopathic effect of Albizia saman F. Muell on three widely cultivated Indian crop species. J Vet Res. 2013;5:13-18.

21. Magnus KE, Seaforth CE. Samanea Saman Merill. The Rain Tree: A Review. J Trop Sci. 1965;7:6-11.

22. George-Staples WR, Elevitch C. Species profile for pacific Islan agroforestry. 2006;1: 1-13.

23. Orwa. Agroforestry Database 4.0.2009

24. Isika Ogunwande A, Tameka Walker M, William Setzer N. Nat Prod Communication. 2007;2:1314.

25. James-Duke A. Handbook of Energy Crops. 1993;2:677-9.

26. Isika Ogunwande A, Tameka Walker M, William Setzer N, Emmanuel Essien. Volatile constituents from Samanea Saman (Jacq.) Merr. African J. of Biotechnology. 2006;5(20):1890-3.

27. Kohler $\mathrm{K}$, et al. In vitro anti-plasmodial investigation of medicinal plants from $\mathrm{E}$ Salvador Z. Naturforschung C. 2002;57(3-4):277-81.

28. Arulpriya $P$, Laitha $P$, Hemalatha $S$. In vitro antioxidant testing of the extracts of Samanea Saman (Jacq) Merr. Der Chemica Sinica. 2010;1(2):73-9.

29. Ferdous FM, Hossain MK, Rahman MS, Hossain MA, Kabir S. A Mohammad Rashid. Chemical and Biological Investigations of Samanea Saman (Jacq.) Merr. Dhaka Univ. J Pharm Sci. 2010;9(2):69-73.

30. Raghavendra MP, Satich S, Raveesha KA. In vitro antibacterial potential of alkaloids of Samanea Saman (Jacq.) Merr. Against Xanthomonads and human pathogenic bacteria. World J Agric Sci. 2008;4(1):100-5.

31. Prasad RN, Viswanathan S, Devi JR, Nayak V, Rajkumar J, Parthasarathy. Preliminary phytochemical screening and antimicrobial activity of Samanea Saman. J Med Plants. Res. 2008;2(10):268-70.

32. Obasi Nnamdi L, Egbuonu A, Ulha Pius O, Ejikeme P. Comparative phytochemical and antimicrobial screening of some solvent extracts of Samanea Saman (Fabaceae or Mimosacease) pods. Afr. J. Pure. Appl. Chem. 2010;4:206-12.

33. Ragasa $C Y$, Galian RF, Arenal M, Vernadette Tan, Chien-Chang Shen. Triterpenes and Sterols from Samanea Saman. Res J Pharm Biological Chemical Sci. 2014;5(4):1501-7.

34. Hartemann P, Hoet P, Proykova A, Fernandes T, Baun A, Jong DW. Nanosilver safety, health and environmental effects and role in antimicrobial resistance. Mater Today. 2015;18(3):122-3.

35. Awwad AM, Salem NM, Abdeen AO, Green synthesis of silver nanoparticles using carob leaf extract and its antibacterial activity. Inter J Industrial Chem. 2013;4(1):29.

36. Khalil KA, Fouad $\mathrm{H}$, Elsarnagawy $\mathrm{T}$, Almajhdi FN. Preparation and characterization of electro spun PLGA/silver composite nanofibers for biomedical applications. Inter J Electrochemist Sci. 2013;8:3483-93.

37. Iravani S. Green synthesis of metal nanoparticles using plants. Green Chem. 2011;13(10):2638-50.

38. Wilson S, Cholan S, Vishnu U, Sannan M, Jananiya R, Vinodhini S, et al. In vitro assessment of the efficacy of free standing silver nanoparticles isolated from Centella asiatica against oxidative stress and its anti-diabetic activity. Der Pharmacia letter. 2015;7(12):194-205.

39. Fatimah IS. Green synthesis of silver nanoparticles using extract of Parkia speciosa Hassk pods assisted by microwave irradiation. J Advanced Res. 2016;7(6):961-9.

40. Subhashini DC Nachiyar V, Saman A. A Green Route for the Reduction of Bulk TIO2. Inter J Chem Tech. Res.2014:6:5137-41.

41. Kirithika T, Bhaigyabati T, Gomathi R, Usha K. Preliminary Phytochemical Screening and Antioxidant Property of various Extracts of various Extracts of albizia saman leaves. Inter J pharm Res Bio-science. 2013;2(1):315-23. 
42. Kumar RA, Shaik R, Yeshwanth. Phytochemical Profile of Three Selected Plants of Delonix Regia, Samanea Saman and Bauhinia Variegata, Eissn. Inter J res pharm Chem. 2014;5(2):1987-90.

43. Shilpa S, Shashidhara S, Anitha S, Manjula S. Evaluation of Anti-Anxiety Activity of Successive Extracts of Samanea Saman Linn. Pharma Sci Monitor. Inter J. Pharma. Sci. 2012;3(4):0976-7908.

44. Ukoha PO, Cemaluk EA, Nnamdi OL, Madus EP. Tannins and other phytochemical of the Samanaea saman pods and their antimicrobial activities. African J Pure Applied Chem. 2011;5(8):237-44.

45. Indrianingsiha AW, Tachibana S, Itohc K. In vitro evaluation of antioxidant and $\alpha$-Glucosidase inhibitory assay of several tropical and subtropical plants. Procedia Environ. Sci. 2015;28:639-48.

46. Vinodhini S, Preethi SM, Fathima NN, Kushwaha SS, Rajeswari DV. Antioxidan and Free Radical Scavenging Activity of Punica Granatum Leaf Extract. Asian J Pharm Clinical Res. 2016;9:140-6.

47. Erharuyi O, Falodun A. Free Radical Scavenging Activities of Methanol Extract and Fractions of Picralima nitida (Apoceanacea). J Applied Sci Environ. 2012;16(3):291-4.

48. Ferdous A, Imam MZ, Tajnin-Ahmed. Antioxidant, Antimicrobial and cytotoxic activities of Samanea Saman (Jacq.) Merr. S J Pharm Sci. 2010;3(1):11-7.

49. Jagessar RC, Mars A, Gomathinayagam S. Selective Antimicrobial properties of Leaf extract of Samanea Saman against Candida albicans, Staphylococcus aureus and Escherichia coli using several microbial methods. Am. J Sci. $2011 ; 7(3): 108-19$

50. Thippeswamy S, Praveen P, Manjunath K. Antimicrobial evaluation and phytochemical analysis of a known medicinal plant Samanea Saman (Jacq.) Merr against human and plant pathogenic bacteria and fungi. Inter J Pharm Biological Sci. $2011 ; 2: 443-52$

51. Shanmuga-Kumar SD, Satheesh-Kumar G. Isolation of pithecolobine from the leaf extracts of Samanea Saman saman (Jacq.) Merr and it's in vitro antitubercular screening and related infections. Inter $\mathrm{j}$ innovative pharm Sci res. 2014;2:1098-106.

52. Ajam SM, Salleh S, Al- Khalil S, Sulaiman SF, Cytotoxic activity of Spermine Alkaloids from Samanea Saman against Microbes associated with sick buildings. Inter Conference Environ chemistry Biol. 2012;49:150-5.

53. Vinodhini S, Devi-Rajeswari V. Phytochemical Profiling and Evaluation of Pharmacological Activities of Tribulus Terrestris (Linn.) Seed, inter J Pharm Bio Sci. 2016;7:185-98

54. Zimmet PZ. Diabetes epidemiology as a tool to trigger diabetic research and care. Diabetologia 1999;42(5):499-518

55. Balaraman AK, Singh J, Dash S, Maity TK. Antihyperglycemic and hypolipidemic effects of Melothria maderaspatana and Coccinia indica in Streptozotocin induced diabetes in rats. J Saudi pharm. 2010;18(3):173-8.

56. Babin-Reejo D, Natarajan $P$ Thangathirupathi A. Evaluation of Anti-Diabetic Activity of Samanea Saman (Jacq.) Merr Inter J Res Pharma Nano Sci. 2014;3:352-6.

57. Prabhu S, Vinodhini S, Elanchezhiyan C, Rajeswari D. Evaluation of anti-diabetic activity of biologically synthesized silver nanoparticles using Pouteria sapota in streptozotocin-induced diabetic rats. J Diabetes; 2017. DOI: 10.1111/17530407.12554

58. Girish Gulab Meshram, Anil Kumar, Waseem Rizvi, Tripathi CD, Khan RK. Evaluation of the anti-inflammatory activity of the aqueous and ethanolic extracts of the leaves of Albizzia lebbeck in rats. J Traditional. Complementary. Med. 2016;6(2):172-5

59. Arumugam S, Selvaraj SV, Velayutham S, Natesan SK, Palaniswamy K. Evaluation of anti-ulcer activity of Samanea Saman (Jacq.) Merr bark on ethanol and stress induced gastric lesions in albino rats. Indian J. Pharmacology. 2014 43(5):585-90.

60. Azhar IM, Hasan MM, Mazhar FA. Some biological evaluations of Samanea Saman Pak J Pharmacology. 2009;26:47-53.

61. Lovett J, Ryuntyu M. Allelopathy: Broadening the context. In Allelopathy: Basic and applied aspects. Eds. SJH. Rizvi and V. Rizvi. Chapman and Hall Press. New York. 1992: 11-19.

62. Rizvi SJH, Rizvi V. Allelopathy: basic and applied aspects. Chapman and Hall, London. 1992;480.

63. Oussama O. Allelopathy in two durum wheat (Triticum durum L.) varieties. Agric Ecosys Environ. 2003;96(1):161-3.

64. Ward FM, Daly MJ. Hepatic Disease. In: Clinical Pharmacy and Therapeutics (Walker R. and C. Edwards Eds.). Churchill Livingstone, New York. 1999;195-212.

65. Sharma A, Chakraborti KK, Handa SS. Anti-hepatotoxic activity of some Indian herbal formulations as compared to Silymarin. Fitoterapia. Inter J Current Pharm Res. 1999;62:229-35.

66. Subramonium A. Pushpangadan P. Development of phytomedicines for liver diseases. Indian J. Pharmacology. 1999;31(3):166-75.

67. Kumar $\mathrm{CH}$, Ramesh A, Kumar JNS, Ishaq BM. A review on hepatoprotective activity of medicinal plants. Inter J Pharm Sci Res. 2011;2(3):501-15.

68. Sindhan V, Velan SS, Rakesh Joshi. Hepatoprotective Activity of Samanea Saman (Jacq) Merr Bark against Ccl4 Induced Hepatic Damage in Albino Rats. Inter J Institutional Pharm Life Sci. 2012;2:2249-6807.

69. Karim AA, Azlan A. Fruit pod extracts as a source of nutraceuticals and pharmaceuticals. Molecules. 2012;17(10):11931-46.

70. Shreenivas S, Kumarappa NS, Rangaswamy MBE. Production of Bioethanol from Different Feed stocks and Performance, Emission Characteristics of Single Cylinder CI Engine. Inter J Res Engineering Sci Technol. 2015;2:2395-0072.

\section{GRAPHICAL ABSTRACT}

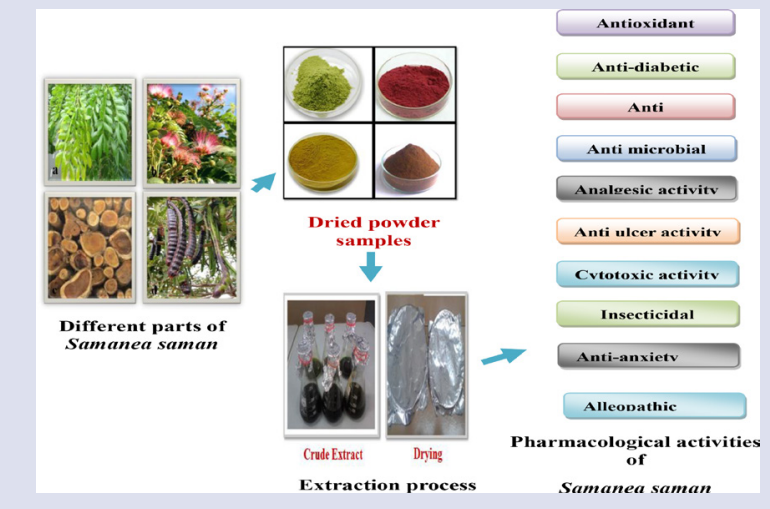

\section{SUMMARY}

- Pharmacological activities and traditional usage of the medicinal plant of Samanea saman has been reviewed in this study.

- Various extracts were evaluated for their antimicrobial activity against the different strains and antioxidant activity was determined.

- It expresses the characteristic compounds of various different parts of Samanea saman.

- Knowledge of chemistry and biological effects behind this medicinal plant Samanea saman has been discussed in this review.

Cite this article: Vinodhini S, Rajeswari DV. Review on Ethnomedical Uses, Pharmacological Activity and Phytochemical Constituents of Samanea saman (jacq.) Merr. Rain Tree. Pharmacog J. 2018;10(2):202-9. 